\title{
Bacterio-Informatics: Identifying the cause of Hansen's disease and establish a remedy for the same
}

\author{
Preenon Bagchi* and Mary Jenifa R. \\ *Azyme Biosciences Pvt. Ltd., Bangalore-560069, preenonb@yahoo.com \\ S.R.M. Arts \& Science College, Kattankulathur-603 203
}

\begin{abstract}
Leprosy or Hansen disease is a slowly progressive infection caused by Mycobacterium leprae, affecting the skin and peripheral nerves and resulting in disabling deformities. Studies show that $M$. leprae binds to nasal epithelial cells in human after binding to fibronectin, using Beta-integrins (ITGB1) as receptors. The corresponding component on $M$. leprae, which binds to fibronectin, Fibronectin Attachment Protein (FAP), has been identified . The 3D structure of both the human (ITGB1) and M.leprae (FAP-L) protein involved in this mechanism are modeled using homology modeling. Hemolin, an insect-immune protein belonging to the immunoglobulin superfamily is found to have an efficient defense system against bacterial infections. So this protein is selected and its 3D structure is modeled too. The active compound Anacardic acid of marine brown alga Fucus vesiculosus and the compound Polyhydroxylated fucophlorethol of Anacardium occidentale is found to have antibacterial activity. Their structure was drawn using Chemsketch, combined and converted to *.pdb. The combination is docked with Hemolin protein. This docked compound is again redocked with the human ITGB1 protein using GRAMM-X.

Again, the combination (Anacardic acid and Polyhydroxylated fucophlorethol) was docked with M. leprae which proves that the combination can be effective in curing Hansen disease.
\end{abstract}

Keywords- Hansen Disease, Leprosy, Beta-integrin, Bioinformatics, Mycobacterium leprae, Ayurveda, Homology modeling, Docking.

\section{Introduction}

Leprosy is a chronic disease. Leprosy (from the Greek lepi meaning scales on a fish), or Hansen's disease (HD), caused by the bacteria Mycobacterium leprae and Mycobacterium lepromatosis [1]. This particularly affects the mucous membranes of the skin and nerves. Leprae is, for the most part, contained within the skin, but leprosy is likely to be transmitted from person to person through aerosols from lesions in the upper respiratory tract. Inhaled $M$. leprae, like $M$. tuberculosis, is taken up by alveolar macrophages and disseminates through the blood, but grows only in relatively cool tissues of the skin and extremities [2]. Nerve degeneration causes skin anesthesia and skin and muscle atrophy that render the patient liable to trauma of the affected parts, with the development of indolent skin ulcers. Contractures, paralyses, and autoamputation of fingers or toes may ensue [3]. Facial nerve involvement can lead to paralysis of the eyelids, with keratitis and corneal ulcerations. The invasion of Schwann cells and axons by $M$. leprae leads to demyelination and axonal degeneration. $M$. leprae almost exclusively infects macrophages and Schwann cells. Various receptor- mediated mechanisms, similar to those exploited for invasion of macrophages, may play a role in the invasion of human Schwann cells by mycobacteria $[1,3]$. Candidates are Fc receptors, complement receptors, the Fibronectin binding protein, and mannose receptors. Since $M$. leprae binds to nasal epithelial cells after binding to Fibronectin, using Beta-integrin as receptors the study was made on ITGB1 protein. For a long time this disease was seen as a curse, a hereditary disease and its patients used to be stigmatized. Cases of this disease have been reported as early as 650 BC and the Christian Bible talks a lot about it. But it's not as contagious as the Bible stories make us believed. Patients of this disease used to be stunned. This disease no longer cause a threat to the United States but is a major problems in the third countries specially India, Brazil and some parts of Africa. M.leprae is an obligate parasite that once it attacks the human body can take a long time to show symptoms. M.leprae, also known as Hansen's coccus spirilly, mostly found in warm tropical countries, is a bacterium that causes leprosy (Hansen's disease). It is an intracellular, pleomorphic, acid-fast bacterium [4].

\section{Beta-Integrin 1 Receptor}

$M$. leprae binds to nasal epithelial cells after binding to fibronectin, using Beta-integrins as receptors. After binding of the bacterium to the Fibronectin using Beta-integrins, this fibronectin significantly enhanced both attachment and ingestion of $M$. leprae by T24 epithelial and J S I Schwannoma cell lines. Beta-Integrin is a known receptor for fibronectin. Therefore, fibronectinintegrin mediated binding mechanisms could play a role in the pathogenesis of cells expressing these proteins. Beta-Integrin (also known as fibronectin receptor, Beta sub unit CD29 or integrin VLA4 beta sub unit) has a molecular weight of $88.465-\mathrm{kDa}$. It is a type-I membrane protein and is a receptor for fibronectin, laminin and vitronectin. It is widely expressed in skin, liver, skeletal muscle, cardiac muscle, placenta, umbilical vein, endothelial cells, neuroblastoma 
cells and astrocytoma cells. It is a transmembrane receptor protein present in the extracellular matrix and cytoskeleton. Generally Integrins are receptors that mediate attachment between a cell and the tissues surrounding it, which may be other cells or the extracellular matrix (ECM). They also play a role in cell signaling and thereby define cellular shape, mobility, and regulate the cell cycle $[5,6]$.

Fibronectin (fn)-attachment protein (faps)

Fibronectin (FN)-attachment proteins (FAPs) are a family of mycobacterial proteins that have been shown to facilitate FN-mediated attachment and internalization of mycobacteria invitro. This family contains bacterial fibronectin-attachment proteins (FAP). Family members are rich in alanine and proline, are approximately 300 long, and seem to be restricted to mycobacteria. These proteins contain a fibronectin-binding motif that allows mycobacteria to bind to fibronectin in the extracellular matrix. Other names for Fibronectin attachment protein are Alanine and proline-rich secreted protein apa precursor (Mycobacterium leprae), FN-binding protein, Mycobacterium leprae, FAP-L (M. leprae), APA_MYCLE, Antigen 43L, FAP-L [7]. Fucus vesiculosus, known by the common name bladder wrack, is a seaweed found on the coasts of the North Sea, the western Baltic Sea, and the Atlantic and Pacific Oceans. Fucus vesiculosus is a perennial seaweed. Its root is a hard, flattish disk. The frond or thallus ranges from a few inches to 4 feet in length, and from 2 lines to an inch in width, is flat, furnished with a midrib throughout its length, occasionally twisted in a spiral manner, repeatedly dichotomous, the angles of the dichotomy acute, except when a solitary vesicle happens to be placed there; the sterile branches are obtuse, and often notched at the extremity. Fucus vesiculosus contains a Polyhydroxylated fucophlorethol that shows antibacterial activity against both $\mathrm{G}+$ and $\mathrm{G}$ - bacteria [8]. The cashew (Anacardium occidentale; syn. Anacardium curatellifolium A.St.-Hil.) is a tree in the flowering plant family Anacardiaceae. The cashew tree is evergreen. It grows up to 12 metres high and has a spread of 25 metres. Its extensive root system allows it to tolerate a wide range of moisture levels and soil types, although, commercial production is advisable only in well-drained, sandy loam or red soils. Cashew trees are most frequently found in coastal areas. The main commercial product of the cashew tree is the nut. In the main producing areas of East Africa and India, $95 \%$ or more of the apple crop is not eaten, as the taste is not popular. The cashew nutshell liquid (CNSL), a by-product of processing cashew, is mostly composed of anacardic acids. These acids have been used effectively against tooth abscesses due to their lethality to grampositive bacteria. They are also active against a wide range of other gram-positive bacteria. Many parts of the plant are used by the Patamona of Guyana medicinally. The bark is scraped and soaked overnight or boiled as an antidiarrheal. Seeds are ground up into powders used for antivenom for snake bites. The nut oil is used topically as an antifungal and for healing cracked heels. The seed is surrounded by a double shell containing a dermatogenic phenolic resin, anacardic acid, a potent skin irritant. The cashew nutshell liquid (CNSL), a by-product of processing cashew, is mostly composed of anacardic acids. These acids have been used effectively against tooth abscesses due to their lethality to gram-positive bacteria. They are also active against a wide range of other grampositive bacteria [9, 10]. A protein called Hemolin has been found to be produced in response to bacteria and virus in several crustaceans and insects and is believed to have a role in protecting these organisms from infection. Hemolin was identified and sequenced from the budworm, Heliothis virescens as well as the corn earworm, Helicoverpa zea. Larvae from these species of insect are found to produce more Hemolin when infected with bacteria but not when challenged with virus. Hemolin, an insectimmune protein belonging to the immunoglobulin superfamily is found in Helicoverpa zea [11, 12]. Most of the insects have an efficient defense system against infections. Their antibacterial immune proteins have been well characterized. However, the molecular mechanisms by which insects recognize foreignness are not yet known.

\section{Methodology \\ Softwares/Web Servers used}

1) modeller $9 v 7$

MODELLER (copyright (C) 1989-2008 Andrej Sali)

http://salilab.org/index.html

2) Swiss-PdbViewer v4.01 by Nicolas Guex , Alexandre Diemand, Manuel C. Peitsch , \& Torsten Schwede (Swiss Institute of Bioinformatics)

http://spdbv.vital-it.ch/index.html

3) ACD/ChemSketch Freeware, version 11.00, Advanced Chemistry Development, Inc., Toronto, ON, Canada, www.acdlabs.com, 2008.

4) RAMPAGE: Assessment of the Ramachandran Plot

MolProbity | Crystallography and Bioinformatics Group

http://mordred.bioc.cam.ac.uk/ rapper/rampage.p hp

S.C. Lovell, I.W. Davis, W.B. Arendall III, P.I.W. de Bakker, J.M. Word, M.G. Prisant, J.S. Richardson and D.C. Richardson (2002) Structure validation by Calpha geometry: phi,psi and Cbeta deviation. Proteins: Structure, Function \& Genetics. 50: 437-450. 
5) ArgusLab 4.0.1, Mark A. Thompson, Planaria Software LLC, Seattle, WA

http://www.arguslab.com

6) HEX 5.1

University of Aberdeen, Scotland, UK

http://www.csd.abdn.ac.uk/hex/

7) PATCHDOCK

Structural Bioinformatics group at Tel -Aviv University

http://bioinfo3d.cs.tau.ac.il/PatchDock/index.html

8) GRAMM-X: Protein Docking Web Server v.1.2.0

Center for Bioinformatics: The University of Kansas

http://vakser.bioinformatics.ku.edu/resources/gra $\mathrm{mm} /$ grammx/

The target protein fibronectin receptor, beta polypeptide (ITGB1) with accession number AAH20057 was first searched in NCBI database and the aminoacid was retrieved as fasta format. Homology modeling studies were done using modeller9v7 using templates (templates were retrieved via BLAST search engine) 1JV2B, 1L3YA, \& 1TOZA and ten models (3D structures) of ITGB1 protein were generated. The models generated by Modeller is analyzed by Rampage Ramachandran Plot server and the best stable model is selected. Again, the 3D model of the protein FAP-L (accession number AAB34676, taken from NCBI) was modeled using templates retrieved from BLAST search tool. The templates were 2ZLEA, 2EXHA, \& 2EXKA. Ten models were generated and best was selected by Rampage Ramachandran Plot analysis. For proposed treatment principal alkaloids from Anacardium occidentale (cashew), Fucus vesiculosus (Brown fungi) were selected. Again, protein Hemolin found to have anti-bacterial activity was selected. The 3D structure of the protein HEMOLIN (ncbi accession number ACC91898 was modeled using templates retrieved from BLAST search tool. The templates were 1CS6A, 3DMKA, \& 3NCMA. Ten models of Hemolin protein was generated by modeller. The best was selected by analysis with Rampage Ramachandran Plot Server. The structure of ANACARDIC ACID and POLYHYDROXYLATED FUCOPHLORETHOL was drawn using ACD/Chemsketch and converted to .*pdb using argus lab software. This combination was docked with Hemolin protein using HEX software. Again, the docked combination (Hemolin, Anacardic Acid and Polyhydroxylated Fucophlorethol) was docked with ITGBI protein using GRAMM-X software. Again, Anacardic Acid and Polyhydroxylated Fucophlorethol combination was docked with FAP-L protein using HEX software.

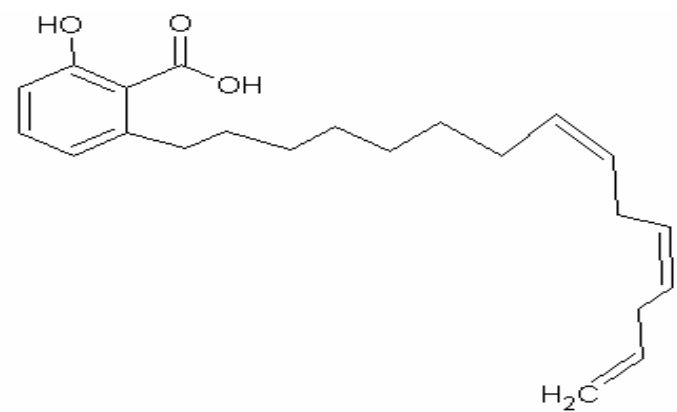

Fig. 1-Chemical structure of anacardic acid drawn using ACD/Chemsketch software

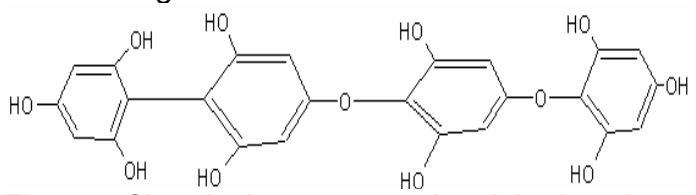

Fig. 2- Chemical structure of polyhydroxylated fucophlorethol drawn using ACD/Chemsketch software<smiles>C=CC/C=C\C/C=C\CC(O)(CC=C)CCCCCc1cccc(Oc2cc(O)cc(O)c2-c2c(O)cc(Oc3c(O)cc(Oc4cc(O)c(O)cc4O)cc3O)cc2O)c1C(=O)O</smiles>

Fig. 3- Combined Structure of anacardic acid \& polyhydroxylated fucophlorethol

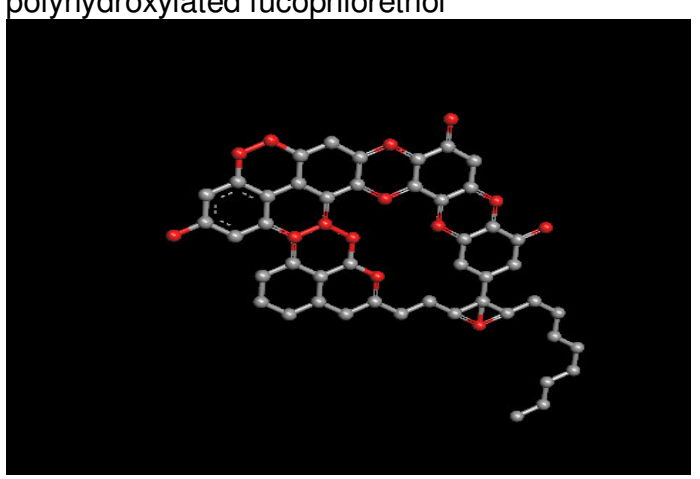

Fig. 4- Combined Structure of anacardic acid \& polyhydroxylated fucophlorethol in Argus lab $\left({ }^{*} . \mathrm{pdb}\right)$

\section{Result}

The ITGB1.pdb protein obtained after homology modeling was analyzed with Ramachandran Plot server. The results obtained for best model (\#7) are as follows:

Number of residues in favoured region ( $98.0 \%$ expected): 694 (87.2\%)

Number of residues in allowed region ( 2.0\% expected) : $71(8.9 \%)$ 
Number of residues in outlier region : 31 $(3.9 \%)$

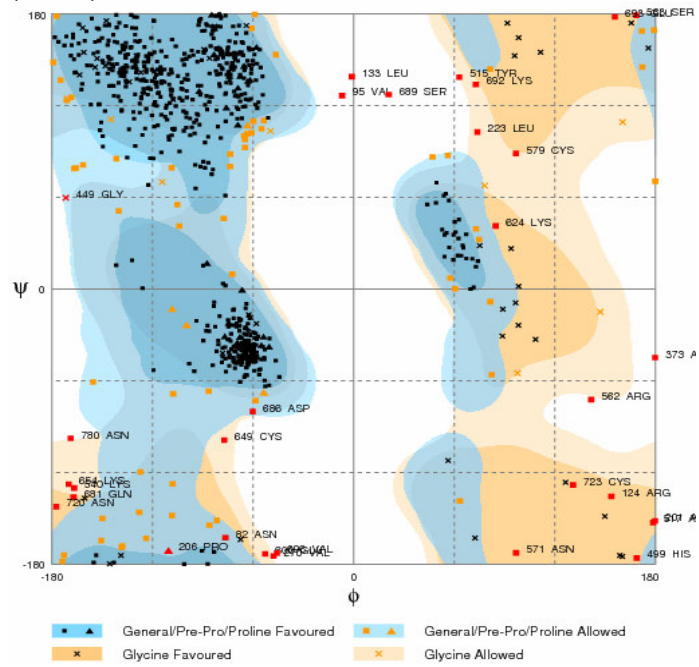

Fig. 5- Ramachandran Plot analysis ITGB1.pdb (model 7)

The FAP-L.pdb protein obtained after homology modeling was analyzed with Ramachandran Plot server. The results obtained for best model (\#7) are as follows:

Number of residues in favoured region ( $98.0 \%$ expected): 248 (87.0\%)

Number of residues in allowed region ( 2.0\% expected): 27 (9.5\%)

Number of residues in outlier region : 10 (3.5\%)

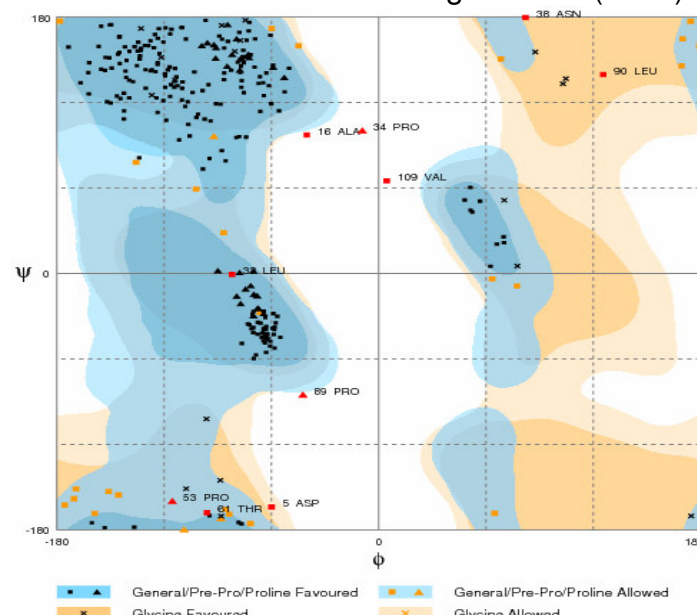

Fig. 6- Ramachandran Plot analysis FAP-L.pdb (model 7)

The HEMOLIN.pdb protein obtained after homology modeling was analyzed with Ramachandran Plot server. The results obtained for best model (\#2) are as follows:

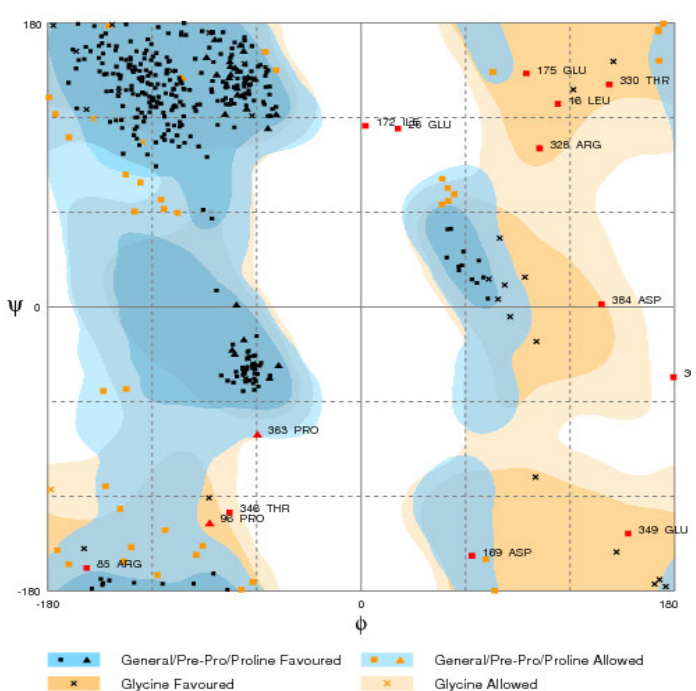

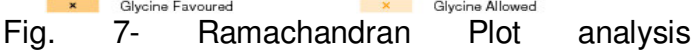
HEMOLIN.pdb (model 2)

Number of residues in favoured region ( $98.0 \%$ expected): 362(86.6\%)

Number of residues in allowed region ( 2.0\% expected): $42(10.0 \%)$

Number of residues in outlier region : 14 (3.3\%)

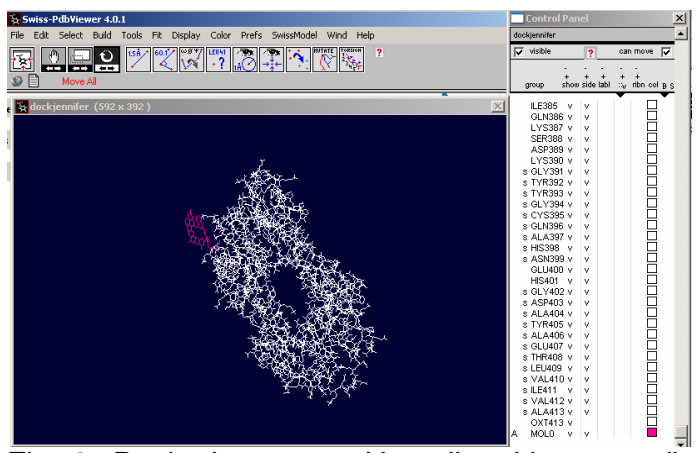

Fig. 8- Docked structure Hemolin with anacardic acid \& polyhydroxylated fucophlorethol (visualization in SPDBV)

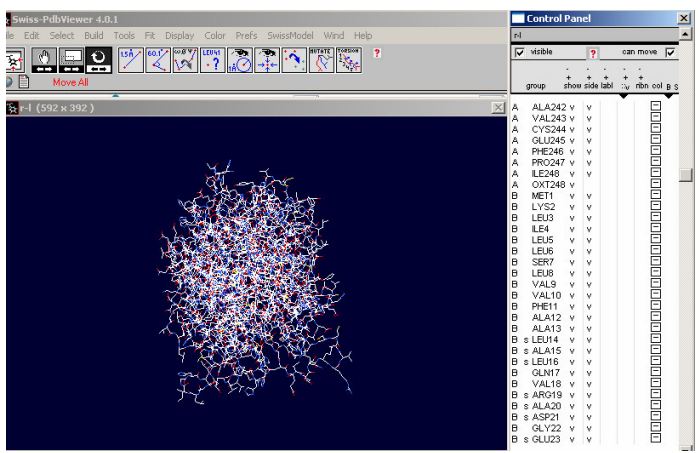

Fig. 9- Docked structure ITGBI with Hemolin, anacardic acid \& polyhydroxylated fucophlorethol combination (visualization in SPDBV) 


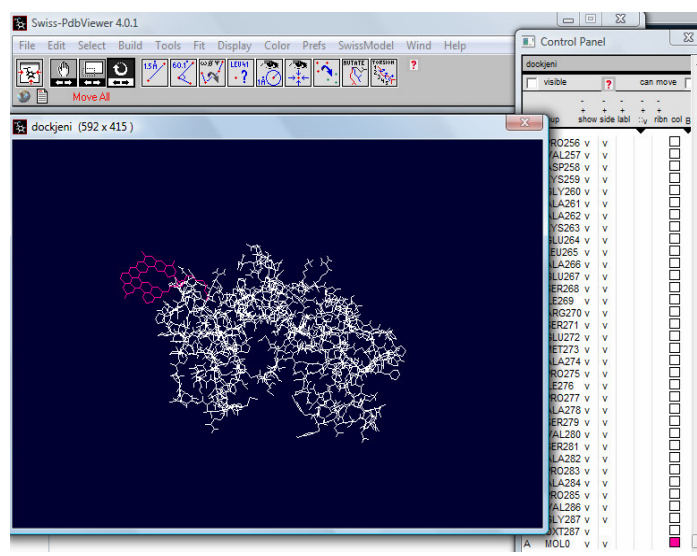

Fig. 10- Docked structure FAP-L with anacardic acid \& polyhydroxylated fucophlorethol combination (visualization is SPDBV)

\section{Discussion}

This in-silico-herbal work highlights two important landmark achievements towards this disorder: (i) mutation as one of the cause of Hansen disease and identification of the mutant protein, (ii) application of an insect-immune protein in combination with Indian herbal medication towards treatment/cure of this disorder. These achievements should prove to be a boon towards treating Leprosy. For a decade, Leprosy was treated as curse and hence the patients illtreated. As per the reports India tops the list of leprosy patient. Henceforth the authors wish successful cure towards this disorder and also hope that they may return to the normal life. Indian herb Anacardium occidentale, brown alga, Fucus vesiculosus and hemolin, an insectimmune protein is found to have anti-bacterial property, henceforth authors wish to highlight their application to treat patients suffering from leprosy.

\section{Conclusion}

The successful docking of ITGB1.pdb protein with Hemolin, anacardic acid \& polyhydroxylated fucophlorethol combination combination proves that the combination can be effective in the treatment of Hansen disease. The Patchdock server gave the docking score as 20758. Also, successful docking of FAP-L.pdb protein with anacardic acid \& polyhydroxylated fucophlorethol combination proves that the herbal combination can be effective treating Hansen disease (docking score obtained as output from patchdock server 9182).

\section{References}

[1] Tahziba Hussain (2007) Critical Reviews in Microbiology, 33(1), 15-66.

[2] Sajous's analytical cyclopædia of practical medicine (1904)
[3] Textbook of Military Medicine (1976) Published by the Office of The Surgeon General Department of the Army, United States of America, 1-15

[4] Leprosy And Stigma In The South Pacific: Camaraderie In Isolation Dorothy Mcmenamin (2009), 1-320

[5] Roura-Mir C., Wang L., Cheng T.Y., Matsunaga I., Dascher C.C., Peng S.L., Fenton M.J., Kirschning C., Moody D.B. (2005) The Journal of Immunology, 175 (3):1758-66

[6] Simon Keely, Louise E. Glover, Christopher F. MacManus, Eric L. Campbell, Melanie M. Scully, Glenn T. Furuta, and Sean P. Colgan (2009) The FASEB Journal, 23, 1338-1346

[7] Secott T. E., Lin T. L. and Wu C. C. (2002) Infect Immun. 70(5), 2670-2675

[8] Sandsdalen E., Haug T., Stensvåg K. and Styrvold O. (2003) World J Microbiol Biotechnol 19(8), 777-782

[9] Cashew nut history and information a dictionary of food and nutrition (2005) originally published by oxford university press 2(1), 33-38

[10] Isao Kubo, Masamitsu Ochi, Paulo C. Vieira, and Sakae Komatsu (1993) J. Agric. Food Chem 41(6), 1012-1015

[11] Terenius O., Popham H.J., Shelby K. (2009) Developmental and Comparative Immunology. 33:1176-1185.

[12] Sun S.C., Lindstrom I., Boman H.G., Faye I. and Schmidt O. (1990) Science, 250(4988), 1729-1732. 